\title{
Marjinal alanlar için alternatif katma değer bitkisi: Styrax officinalis $\mathbf{L}$.
}

\author{
Ayşe Betül Avcı a,* (D), R. Refika Akçalı Giachino ${ }^{\mathrm{b}}$ (D), Serdar Gökhan Şenol ${ }^{\mathrm{c}}$ (ic)
}

Özet: Genel olarak 'Tesbih ağacı' ya da ‘ayı fındığı' olarak tanınan Styrax officinalis L. bitkisi orman alanları dışında, makilik ya da çorak alanlarda da yetişebilmesi, tohumunda bulunan yüksek yağ içeriği ve çok yönlü kullanım alanlarına sahip olması sebebiyle oldukça önemli bir bitkidir. Her ne kadar son yıllarda yapılan çalışmalar artmış olsa da yine de bitki hak ettiği ilgiyi görememiştir. Bu sebeple bitkiyi tanıtmak ve yapılan çalışmaları bir araya getirmek amacıyla bu derleme hazırlanmıştır.

Anahtar Kelimeler: Ayı findığı, tesbih ağacı, yağlı tohum, biyodizel, Styracaceae, Styrax

\section{Alternative cash crop for marginal areas: Styrax officinalis $\mathbf{L}$.}

Abstract: Styrax officinalis L. is generally known as 'rosary tree' or 'bear hazelnut' is a very important medicinal plant can grow in shrub or barren fields outside of forest areas, its high oil content in its seed and its versatile uses. Although studies have increased in recent years, the plant still has not received the attention it deserves. For this reason, this compilation has been prepared in order to introduce the plant and bring together the studies. Keywords: Styrax officinalis, oilseed, biodiesel, Styracaceae, Styrax

\section{Giriş}

Styrax officinalis L. Styracaceae familyasına ait, çok yıllık, odunsu, çalı formunda, alternatif bir yağlı tohum bitkidir. Genellikle "Storax ağacı" olarak bilinir (Venditti vd. 2018; Jaradat 2020). Storax, Türkiye'de bölgelere göre değişiklik göstererek 'Ayı findığı, Tesbi çalısı, Tesbih ağac1, Yaban ayvası, Zanzalak, Karagünlük' gibi isimler ile anılmaktadır. Akdeniz ikliminde, yüksek maki veya meşe-çam ormanlarında, 0-1500 m rakım arasında yaygın olarak görülebilmektedir. Kireçtaşı ve tortul kayaçlarını ve alkali içeren toprakları tercih eden bitki, maki topluluğu, kızılçam, sedir orman alt örtüsünde ve ormanlarındaki açıklıklarda ve çeşitli habitatlarda yetişebilmektedir. Çok dallı, yuvarlak taca sahip, $6 \mathrm{~m}$ ye kadar boylanabilen, yaprak döken çalılar. Yaprakları basit, geniş eliptikten ovata kadar değişen şekillerde 4.59.5* 3.7-6.5 cm, 5-7 çift yanal damarlı, parlak yeşil ve alt yüzeyde yoğun yıldızsı ve yünsü tüylü. Hoş kokulu beyaz renkli çiçekleri salkımlarda 3-6 adet. Çanak yapraklar yoğun yıldızsı-yünsü tüylü, 5 adet. Taç yapraklar 5-8 adet, beyaz renkli, $1.5 * 0.6 \mathrm{~cm}$. Erkek organlar 12 adet, taç yapraklara eşit boyda. Meyve küremsi, 1.2-1.4 cm çapında, yoğun yıldızsı-yünsü tüylü, uçtan açılıcı. Nisan ve mayıs ayında çiçeklenir. (Şekil 1). Meyveleri sert ve kabuk oranı nispeten yüksek kahverengi tohumlar içerir. Tohumların yağ içeriği yaklaşık olarak \%50 civarındadır (Vardar ve Oflas 1973). $\mathrm{Bu}$ yağın \%90'dan fazlası doymamış yağ asidi formundadır. Yaklaşık olarak \%70 linoleik asit, \%19 oleik asit, doymuş yağ asitlerinden $\% 6$ palmitik asit ve $\% 2$ stearik asit içermektedir (Cesur vd. 2018).

Styrax türleri, Akdeniz havzasında, Asya'nın güneydoğu ve doğu bölgelerinde, Amerika'nın tropikal kuzey ve Güney kesimlerinde yayılış göstermektedir. Özellikle, İtalya, Arnavutluk, Yunanistan, Girit, Rodos ve Kıbris adas1, Türkiye, Lübnan, İsrail ve Suriye'ye kadar uzanan bir büyüme alanına sahip tipik bir Doğu Akdeniz türüdür (Venditti vd. 2018). Türkiye'de ise Güneydoğu, Akdeniz, Ege, Marmara ve Orta Karadeniz bölgelerinde doğal olarak yayılış göstermektedir (Şekil 2), (Yeşilyurt ve Cesur 2020). a Ödemiş Meslek Yüksekokulu, Ege Üniversitesi, İzmir

b Ziraat Fakültesi Tarla Bitkileri Bölümü, Ege Üniversitesi, İzmir

c Fen Fakültesi Biyoloji Bölümü-Botanik Anabilim Dalı, Ege Üniversitesi, İzmir

Corresponding: ayse.betul.avci@ege.edu.tr Received: 19.09.2021, Accepted: 17.10.2021
Citation: Avcı, A.B., Akçalı Giachino, R.R., Şenol, S.G. (2021). Marjinal alanlar için alternatif katma değer bitkisi: Styrax officinalis L. Theoretical and Applied Forestry 2: 57-60. doi: 10.53463/tafor.2021vol1 iss2pp57-60 

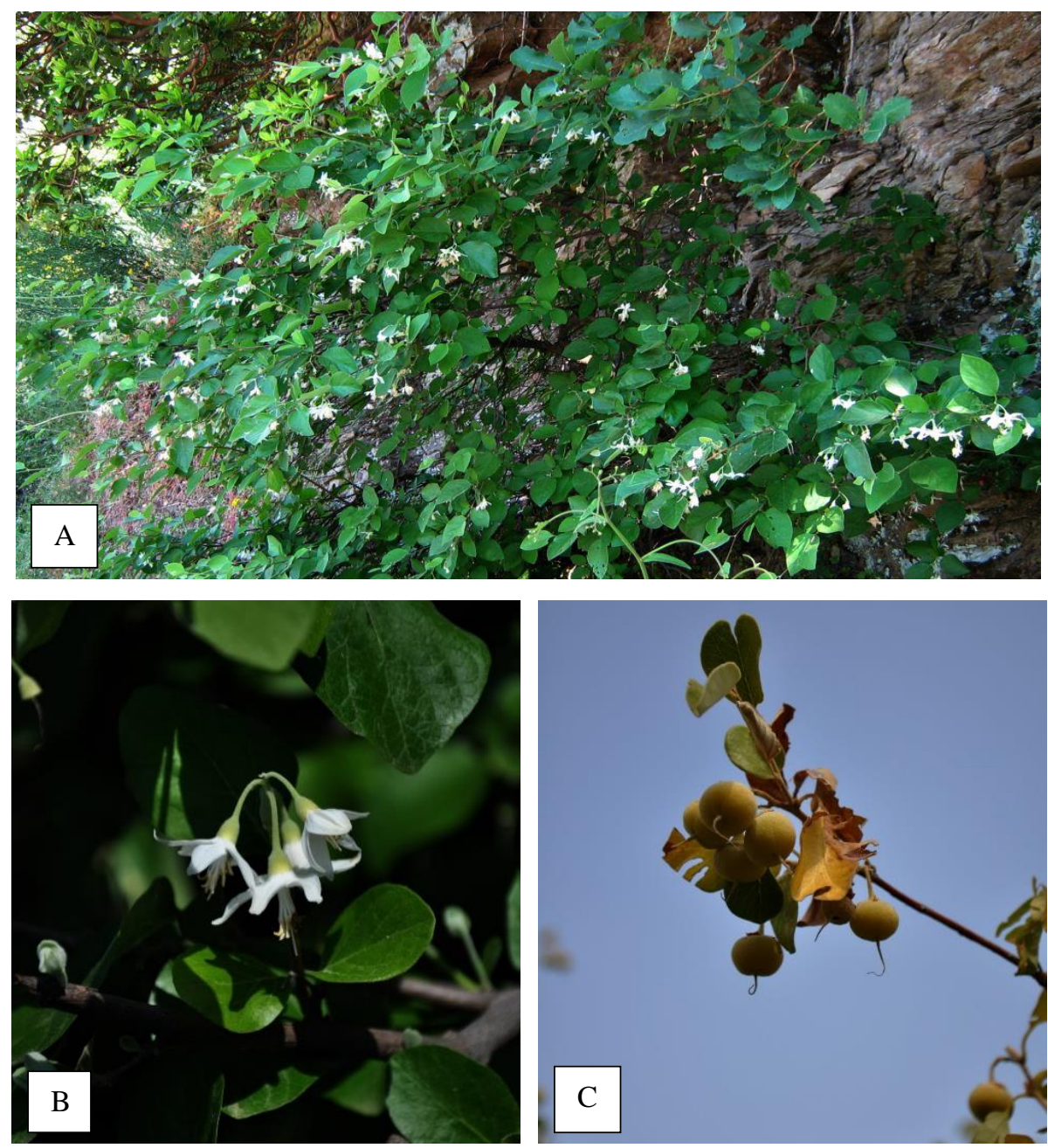

Şekil 1. S. officinalis; A. Genel görünüş, B. Çiçek durumu, C. Meyve (Orijinal)

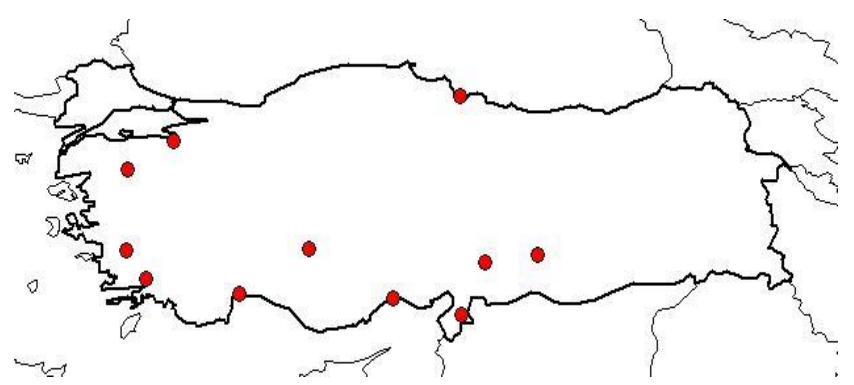

Şekil 2. S. officinalis' in dağılım haritası (TUBİVES, 2021)

Styracaceae familyasının, 10 cins ve bunlara bağlı yaklaşık 130 takson olduğu bilinmektedir (Davis 1982; Fritsch 1999). Türkiye'de Styrax officinalis L. subsp. officinalis olarak tek takson ile temsil edilmektedir (Güner vd. 2012). Ayrica, S. officinalis L. subsp. officinalis, doğu Akdeniz bölgesine özgü, S. officinalis L. subsp. redivus (Torr.) Thorne ve subsp. fulvecens (Eastw.) A. E. Murray, Kaliforniya'ya endemik, Styrax platanifolius var. texanus (Cory) B.L.Turner ve Styrax platanifolius var. youngiae (Cory) B.L.Turner Teksas ve kuzey Meksika'da yakın akraba taksonlardır (Fritsch 1996).

\subsection{Kullanım alanları}

Geniş yayılışı ile ormanlık alanların alt öğesidir ve yağ içeriği bakımından zengin tohumlara sahip olması onu endüstriyel açıdan önemli kılmaktadır (Demiray vd. 2013). Storax tarım arazileri dişında, çorak ve hasarlı yüzeylerde, orman alanları ve hatta \%60-70 gölgede yetişebildiği için endüstriyel anlamda daha değerlidir (Yeşilyurt ve Cesur 2020).

Geleneksel tıpta, idrar yolu enfeksiyonları, solunum sistemi enfeksiyonları ve dermatit tedavisinde kullanılmaktadır (Jaradat vd. 2018). Storax olarak 
bilinen kokulu reçine, bu çalıdan gövdenin yaralanmasıyla elde edilmektedir. Storax gövde reçinesi geleneksel tıpta balgam söktürücü ve antiseptik balsam olarak kullanılmaktadır. Ayrıca bu balsam eski çağlarda tütsü için kullanılan bir ticaret ürünü olmuştur. Reçinesi nedeniyle Anadolu sığla ağacı (Liquidambar orientalis Mill.) ile karıştırılmaktadır. L. orientalis ten elde edilen reçinenin bileşenleri açısından benzerlik göstermesi, uzun seneler $S$. officinalis ile $L$. orientalis' in aynı isimle anılmasına neden olmuştur (Oflas 1973).

S. officinalis geniş bir şekilde eczacılıkta, parfümeri ve sabun endüstrisinde kullanılır. Ancak iyot değerinin düşük olması boya sanayinde kullanımının mümkün olmayacağını göstermektedir (Vardar ve Oflas 1973). Çiçekleri reçel yapımında kullanılır. Ayrıca süs bitkisi olarak da peyzaj alanlarında dikilmektedir.

Meyveleri insan ve hayvan gıdası olarak değerlendirilmektedir. Bitkinin çeşitli kısımları süpürge, sandalye, çit, sırık ve kamçı üretmek için kullanılmaktadır. Reçinesi Romalılar, Misırlılar, Fenikeliler ve İyonlar tarafindan tütsü ve tedavi amaçlı kullanılmaktaydı. Aslında aromatik (tütsü olarak) ve tedavi edici özellikleri Romalılar, Misırlılar, Fenikeliler ve İyonlar tarafindan iyi biliniyordu (Vardar ve Oflas 1973; Yayla vd. 2002). Styrax spp. etkili bir piretrumsinerjist olarak bilinen bir benzofuran olan egonol içerir (Akgül ve Anıl 2003).

Styrax, yüksek düzeyde uçucu yağ içeren alifatik aldehitler üreten aromatik bir bitkidir. Decanol, gida katkı maddeleri olarak ve parfüm endüstrisinde faydalı olabilecek doğal bir alifatik aldehit kaynağ 1 olarak tanımlanmıştır. Benzil alkol, daha iyi bilinen aromatik alkollerden biri olup, storaksta ( $S$. officinalis ağacından elde edilen bir reçine) enzim uygulanmış veya uygulanmamış kallus kök dokusunda bulunmuştur (Demiray vd. 2013). Ayrica Tayoub vd. (2006) yaprak uçucu yağının ana bileşenini (E)-2-heksenal, oktanol ve geraniol olarak belirlemiştir.

Bitkinin meyveleri yüksek oranda saponin maddesi içerdiğinden geçmişte temizlik malzemesi olarak kullanılmıştır. Ayrıca çiçekleri bal üreticileri tarafından değerlendirilmektedir.

S. officinalis tohumu ve yağı, biyodizel endüstrisi için yeni ve önemli bir alternatif enerji kaynağı ve potansiyel bir hammadde olarak önerilmektedir (Yesilyurt ve Cesur 2020).

\subsection{Yapılan çalışmalar}

Farklı çevre koşullarının S. officinalis tohumunun fiziksel ve kimyasal özelliklerine etkisinin araştırıldığ 1 bir çalışmada, Mersin, Hatay ve Kahramanmaraş'ın farklı yerlerinden toplanan $S$. officinalis tohumlarının yağ içeriğinin \%44.3 ile \% 60.3 arasında değişim gösterdiği saptanmıştır. Yağ asidi kompozisyonları değerlendirildiğinde ise en baskın yağ asitleri oleik (\%45.50) ve linoleik (\%37.74) asitler olarak belirlenmiş ve $S$. officinalis tohum ham yağının biyodizel gibi alternatif bir yakıt üretmek için yeni bir hammadde olarak değerlendirilebileceği sonucuna varılmıştır (Cesur 2019).

S. officinalis bitkisinden elde edilen ekstraktların Salvia sclarea L. fide büyümesi üzerine etkisinin araştırıldığ bir diğer çalışmada ise, S. officinalis' den elde edilen meyve kabuğu ve tohum kabuğu ekstraktlarının S. sclare tohumlarının çimlenmesi ve fide büyümesi üzerinde önemli bir inhibitör etkiye sahip olduğu belirlenmiştir (Coşge, Şenkal ve Uskutoğlu 2021).

S. officinalis tohum yağının biyo-bazlı yağ üretimi için yapılan performans analizi ve kimyasal sentez için yağın sürtünme ve aşınma analizi, kimyasal olarak işlenmiş $S$. officinalis yağının, temas halindeki parçaların sürtünmesini ve aşınmasını azaltmada daha iyi sonuçlar göstermiştir (Singh vd. 2021).

Eser vd. (2019) S. officinalis yapraklarının kimyasal bileşimini farklı fenolojik dönemlerde araştırmışlar ve en yüksek ham protein değerini, en düşük nötr deterjan fiber, asit deterjan fiber, asit deterjan lignin, hücre içeriklerinin erken çiçeklenme döneminde olduğunu ve bölgesel farklılıklar göz önüne alındığında Styrax çalılarının çiçeklenme döneminin sonuna kadar otlatılabileceğini bildirmişlerdir.

Pazar ve Akgül (2015) S. officinalis meyve kabuğunda yaptıkları fitokimyasal çalışmada; Americanin A ve egonololeat bileşiklerinin varlığını ilk kez rapor etmişlerdir.

Fritsch (1996), Akdeniz bölgesi, Kaliforniya, Teksas ve kuzey Meksika'ya özgü S. officinalis popülasyonları içindeki ve arasındaki genetik çeşitliliğin izozim elektroforezi analizi ile değerlendirmiş ve kıtalararası ayrımın aynı taksonomik türün üyeleri arasında meydana gelmesi bakımından önemli olduğunu vurgulamıştır.

S. officinalis'in tohum çimlenmesi üzerine yapılan çalışmada çatlama ve ekim zamanının etkileri araştırılmış ve en yüksek çimlenme yüzdesi \%56 ile, ekilen çatlamış tohumlardan elde edilmiştir (Yücedağ 2015). Araştırmac1 yüksek çimlenme yüzdesi elde etmek için ekimden önce tohumların çatlatılması ve Eylül ayı sonlarında ekilmesi gerektiğini bildirmiştir.

Styrax benzoin reçineleri ancak Endonezya (Sumatra ve Java), Laos, Tayland ve Vietnam gibi birçok Doğu Asya ülkesinde endemik olan Styrax cinsine ait ağaçların kabuğuna derin kesikler yapıldıktan sonra üretilebilir. Türkiye' de yapılan benzer bir çalışmada ise, İzmirKemalpaşa'dan toplanan S. officinalis örneklerinde, ilk kez rekor benzoin tespit edilmiş ve in vitro olarak yetiştirilen bitki materyallerinin benzoin içeriği hem aşırı bor-plusniasin hem de kokarboksilaz muamelelerini arttırmıştır (Demiray vd. 2013).

Mansour vd. (2016) S. officinalis meyve ekstraktlarının Escherichia coli ve Staphylococcus aureus türlerine karş1 antimikrobiyal etkisini bulmak için disk difüzyon yöntemi kullanmışlar ve metanol ekstrelerin oldukça iyi aktivite gösterdiğini bildirmişlerdir. Sonuç olarak, $S$. officinalis meyve özlerinin enfeksiyon hastalıklarının tedavisinde ve yeni ilaç arayışlarında antibakteriyel ajan olarak kullanılma potansiyeline sahip olabileceğini dile getirmişlerdir. 
Türe ait yaprakların buharla damitılmasıyla elde edilen uçucu yağlarının ana bileşikleri, 2-hexenal (\%17.6), linalool (\%11.9) ve geraniol (\%5.5) olarak bulunmuştur. Çiçeklerin uçucu yağlarının ana bileşiği (\%26.4) linalool iken, tridecanal (\%9.8), dodecane (\%9.6), $\alpha$-terpineol (\%17) ve eugenol (\%9.9) da belirlenmiştir (Tayaub vd. 2006).

Sonuç olarak, tohumlarındaki yüksek yağ içeriği (yaklaşık \%50), bitkinin tarımsal, ormancılık kapsamında yetiştirilmesi halinde önemli ekolojik ve ekonomik faydalar sağlayabileceğini göstermektedir. Anadolu florasının, tropikal kökü olan İndo-Malezya flora kökünden günümüze taşınmış olan $S$. officinalis, ülkemizin bugünü adına bir şanstır. Tropikal bir genetik mirasın Akdenizlileşmesi sonucu bugünkü morfolojik ve fizyolojik karakterlerini kazanan tür, yukarıda da belirttiğimiz gibi ülkemizde, deniz seviyesi ile 1500 m'ler arasında yayılışa sahiptir. Karadeniz, Ege ve Akdeniz Bölgelerinde bu yükseklikler aralığında, tarım dışı ve çorak alanlarda, günümüz Anadolu ikliminde subtropik özelliğe sahip, Muğla, Antalya çevresinde kızılçam orman alt örtüsünde yetişebildiği için endüstriyel anlamda da değerli bir ürün olabilir. Ayrıca, son yıllardaki küresel 1sınma ve iklim değişikliği nedeniyle Mutlak Tarım arazileri, Özel Ürün Arazileri ve Dikili Tarım Arazileri dışında kalan; yerel önemi veya yerel ihtiyaçlar nedeniyle tarıma açılmış marjinal alanlarda yetiştirilebilecek bitkiler kapsamında çok uygun özelliklere sahiptir.

\section{Kaynaklar}

Akgül Y, Anıl H (2003). Benzofurans and another constituent from seeds of Styrax officinalis. Phytochemistry 63: 939-943.

Cesur C (2019). The influence of different environmentaql conditions on the physical and chemical properties of Styrax officinalis L. seed oil. Fresenius Environ Bull. 28(5):4148-4158.

Cesur C, Coşge Senkal B, Uskutoğlu T, Doğan H, Kaya AR, Fidan H (2018). A New industrial plant within the scope of agricultural forestry: Tesbi (Styrax officinalis L.). EJONS International Journal on Mathematic, Engineering and Natural Sciences. 5: 83-90 (in Turkish).

Coşge Şenkal B, Uskutoğlu T (2021). Impacts of Extracts From Styrax officinalis L. on Seedling Growth of Salvia sclarea L. ISPEC Tarım Bilimleri Dergisi, 5(3): 750-756.

Davis P (1982). Flora of Turkey and the East Aegean Islands. Edinburgh, Scotland: Edinburg University Press.
Demiray H, Eşiz Dereboylu A, Yazici ZI, Karabey F (2013). Identification of benzoin obtained from calli of Styrax officinalis by HPLC. Turkish Journal of Botany 37: 956-963.

Eser S, Koç F, Özdüven ML, Cabi E, Eseceli H, Karadağ H (2019). Chemical Contents of Styrax (Styrax officinalis L.) Leaves at Different Phenological Stages. XI ${ }^{\text {th }}$ International Animal Science Conference, p 35. 20-22 October, 2019.

Fritsch P (1996). Isozyme analysis of intercontinental disjuncts within styrax (Styracaceae): Implications for the Madrean-Tethyan Hypothesis". Am J Bot. 83(3): 342-55.

Fritsch PW (1999) Phylogeny of Styrax based on morphological characters with implications for biogeography and infrageneric classification. Systematic Botany 24: 356-378.

Güner AS, Aslan T, Ekim M, Vural M, Babac MT (2012). Türkiye Bitkileri Listesi (Damarlı Bitkiler). Nezahat Gökyiğit Botanik Bahçesi ve Flora Araştırmaları Derneği Yayını, İstanbul.

Jaradat N, Al-Masri M, Zaid AN, Hussein F, Shadid AK, Al Rimawi F, Shayeb K, Sbeih A, Eid A (2018). Assessment of the antimicrobial and free radical scavenging activities of Moluccella spinosa, Helichrysum sanguineum, and Styrax officinalis folkloric medicinal plants from Palestina. Oriental Pharmacy and Experimental Medicine,18:107-114.

Mansour O, Darwish M, Ismail G, Ali E, Ali A (2016). Screening of Antibacterial Activity in vitro of Styrax officinalis L. Covers of Berries Extracts. Research J. Pharm. and Tech. 9(3):119-121.

Oflas S (1973). Batı Anadolu'da Styrax officinalis' in yayılışı ile ilgili ön müşahedeler. Ege Ü. Fen Fak. Genel Botanik Kürsüsü.

Pazar E, Akgül Y (2015). Chemical composition of the endocarps of fruits of Styrax officinalis L. Natural Product Research, 29(15):1466-1468.

Singh Y, Negi P, Yadav A, Tripathi R (2021). Friction and wear characterization of chemically treated Styrax officinalis L vegetable oil, Mate-rials Today: Proceedings,

Tayaub G, Schwob I, Bessiere JM, Rabier J, Masotti V, Mévy JP, Ruzzier M, Girard G, Viano J (2006). Essential oil composition of leaf, flower and stem of Styrax (Styrax officinalis L.) from southeastern France. Flavour and Fragrance Journal, 21: 809-812.

Tubives (2021). Turkish Plants Data Service. http://www.tubives.com/ Acsessed date: 19.09.2021.

Vardar Y, Oflas S (1973). Preliminary studies on the styrax oil. Plant Food Hum Nutr. 22: 145.

Venditti A, Frezza C, Serafini I, Pulone S, Scardelletti G, Sciubba F, Bianco A, Serafini M (2018). Chemical profiling of the fruits of Styrax officinalis L. from Monti Lucretili (Latium region, Central Italy): Chemotaxonomy and nutraceutical potential. Trends in Phytochemical Research, 2: 1-12.

Yayla Y, Alankuş Çalışkan Ö, Anıl H, Bates RB, Stessman CC, Kane VV (2002). Saponins from Styrax officinalis. Fitoterapia, 73,320326.

Yesilyurt MK, Cesur C (2020). Biodiesel synthesis from Styrax officinalis $\mathrm{L}$. seed oil as a novel and potential non-edible feedstock: A parametric optimization study through the Taguchi technique. Fuel, 265:117025.

Yücedağ C (2015). Effects of cracking and sowing time on germination of Styrax officinalis L. seeds. African Journal of Biotechnology, 10(73):16448-16451. 